\title{
Inactivation of lysyl oxidase by $\beta$-aminopropionitrile inhibits hypoxia-induced invasion and migration of cervical cancer cells
}

\author{
XIAOXIAO YANG ${ }^{1}$, SHIFENG LI ${ }^{1}$, WANDE LI $^{2}$, JINGKAO CHEN ${ }^{1}$, XIAO XIAO ${ }^{1}$, \\ YOUQIONG WANG ${ }^{1}$, GUANGMEI YAN ${ }^{1}$ and LIJUN CHEN ${ }^{1}$ \\ ${ }^{1}$ Department of Pharmacology, Zhongshan School of Medicine, Sun Yat-sen University, \\ Guangzhou, Guangdong 510089, P.R. China; ${ }^{2}$ Department of Biochemistry, \\ Boston University School of Medicine, Boston, MA 02118, USA
}

Received September 12, 2012; Accepted October 11, 2012

DOI: $10.3892 /$ or.2012.2146

\begin{abstract}
Tumor invasion and migration are major causes of mortality in patients with cervical carcinoma. Tumors under hypoxic conditions are more invasive and have a higher metastasic activity. Lysyl oxidase (LOX) is a hypoxiaresponsive gene. LOX has been shown to be essential for hypoxia-induced metastasis in breast cancer. However, the direct impact of LOX on cervical cancer cell motility remains poorly understood. Our study revealed that LOX expression at protein and catalytic levels is upregulated in cervical cancer cells upon exposure to hypoxia. Hypoxia induced mesenchymal-like morphological changes in HeLa and SiHa cells which were accompanied by upregulation of $\alpha$-SMA and vimentin, two mesenchymal markers, and downregulation of E-cadherin, an epithelial marker, indicating the epithelialmesenchymal transition (EMT) of cervical cancer cells occurred under hypoxic conditions. Treatment of tumor cells with $\beta$-aminopropionitrile (BAPN), an active site inhibitor of LOX, blocked the hypoxia-induced EMT morphological and marker protein changes, and inhibited invasion and migration capacities of cervical carcinoma cells in vitro. Collectively, these findings suggest LOX enhances hypoxia-induced invasion and migration in cervical cancer cells mediated by the EMT which can be inhibited by BAPN.
\end{abstract}

Correspondence to: Dr Lijun Chen or Dr Guangmei Yan, Department of Pharmacology, Zhongshan School of Medicine, Sun Yat-sen University, 74 Zhongshan Road II, Guangzhou, Guangdong 510089, P.R. China

E-mail: chenlij@mail.sysu.edu.cn

E-mail:ygm@mail.sysu.edu.cn

Abbreviations: LOX, lysyl oxidase; BAPN, $\beta$-aminopropionitrile; $\alpha$-SMA, $\alpha$-smooth muscle actin; EMT, epithelial-mesenchymal transition; ECM, extracellular matrix; NF-кB, nuclear factor kappa B; MMPs, matrix metalloproteinase

Key words: lysyl oxidase, $\beta$-aminopropionitrile, epithelial-mesenchymal transition, invasion and migration, cervical cancer

\section{Introduction}

Cervical cancer is one of the most prevalent types of cancer and a leading cause of cancer-related mortality in women worldwide (1). This cancer is preventable and curable if detected early. However, at the later stage, the cancer metastasizes to the rest of the uterus, bladder, rectum, abdominal wall, pelvic lymph nodes and other organs leading to death (2). There were 529,800 cases and 275,100 deaths due to cervical cancer worldwide in 2008, equivalent to approximately one-tenth of all cancer-related mortalities in women (3). Although surgical resection and radiotherapy can significantly improve noninvasive cancer patient outcome, the invasive cervical cancer remains a significant problem for women (4). Therefore, it is vital to understand the mechanisms of cervical cancer invasion and metastasis in an effort to prevent and treat this disease.

Lysyl oxidase (LOX), a copper-dependent amine oxidase, initiates the process of collagen and elastin crosslinking by oxidatively deaminating specific lysine and hydroxylysine residues located in the telopeptide domains, thus stabilizing the fibrous deposits of these proteins in the extracellular matrix (ECM) (5). LOX is expressed as a 46-kDa preproenzyme and a glycosylated $50 \mathrm{kDa}$ proenzyme. Following secretion into the $\mathrm{ECM}$, the $50-\mathrm{kDa}$ proLOX is further processed by procollagen proteases into the $32-\mathrm{kDa}$ mature species (6). The normal enzymatic activity of LOX plays a critical role in morphogenesis and tissue structural integrity. Abnormal LOX activity can lead to connective tissue disorders such as emphysema (7), osteoporosis (8), cutis laxa (9), Menkes syndrome (10), organ fibrosis, atherogenesis and cardiovascular diseases $(11,12)$.

Perturbation of LOX expression is also involved in carcinogenesis and cancer progression. Markedly, LOX displays a dual role as a tumor suppressor as well as a metastasis promoter in tumorigenesis in its biological functions. LOX antagonizes tumorigenesis. Expression of LOX in ras-transformed fibroblasts decreases the activity of NF- $\mathrm{kB}$ inhibiting cell growth and neoplastic transformation (13). Reduced LOX expression was found in several tumor cell lines (14). LOX propeptide reverses the invasive phenotype of Her-2/neu-driven breast cancer (15). On the other hand, LOX promoted tumor progression. Increased expression of LOX in some tumors was associated with poor prognosis (16). LOX-mediated collagen 
and elastin crosslinking functions as a contributor to tumor ECM stiffening (5). ECM remodeling and stiffening are characteristics of these tumors, promoting tumor motility, migration and rigidity disrupting tissue morphogenesis (17). Matrix remodeling by LOX provides the basis for cell movement important for tumor invasion and migration (18). LOX is known to be essential for hypoxia-induced metastasis in breast cancer (19). Thus, a further understanding of the mechanism(s) by which LOX regulates tumor progression has a potential benefit for novel cancer therapy.

Low oxygen supply is a critical characteristic of solid tumors (20). Hypoxia is a powerful and independent prognostic indicator of poor clinical outcome for patients with cervical and other types of cancer (21). Hypoxia can enhance tumor invasiveness, metastases and resistance to chemotherapy $(22,23)$. The initial steps in metastasis have been proposed to involve an epithelial-mesenchymal transition (EMT) process (24). The EMT turns cells from a typical epithelial morphology into migratory, fibroblastic phenotype (25). The EMT is accompanied by specific changes in some gene expression, such as downregulation of E-cadherin and upregulation of $\alpha$-SMA, vimentin and MMPs, which are most closely correlated with local invasion and metastasis (26). LOX has been described essential for SiHa cells invasion (18). However, it is not clear how LOX promotes tumor progression in cervical cancer.

In this study, we found that LOX protein expression and catalytic activity were upregulated in cervical cancer cells following exposure to hypoxia. Hypoxia turned HeLa and SiHa cells into mesenchymal-like morphology in concomitant with upregulation of $\alpha$-SMA and vimentin and downregulation of E-cadherin. Inhibition of LOX by $\beta$-aminopropionitrile (BAPN) blocked the EMT phenomenon of cervical cancer cells under hypoxia and inhibited cervical cancer cell invasion and migration in vitro providing insights into the prevention and therapy of cervical cancer metastasis.

\section{Materials and methods}

Cell culture and oxygen deprivation. Human cervical cancer cell lines, HeLa and $\mathrm{SiHa}$, were obtained from the American Type Culture Collection (ATCC) and cultured in Dulbecco's modified Eagle's medium (DMEM; Invitrogen, Grand Island, NY, USA) supplemented with $10 \%$ fetal bovine serum (FBS; Invitrogen), in $5 \% \mathrm{CO}_{2}$ at $37^{\circ} \mathrm{C}$. One percent $(1 \%) \mathrm{O}_{2}$ with $5 \%$ $\mathrm{CO}_{2}$ and $94 \% \mathrm{~N}_{2}$ was used as a hypoxia condition in an airtight anaerobic incubator (Coylab 1 Person Polymer $\mathrm{O}_{2}$ Control Glove Boxes) (27).

Western blot analysis. Western blot analysis was performed as previously described (28). Briefly, control and treated cells were lysed in an SDS-PAGE sample buffer. Equal amounts of proteins were fractionated on SDS-PAGE and transferred to polyvinylidene difluoride membranes. After blocking with $5 \%$ non-fat dry milk in TBST (Tris-buffered saline containing $0.1 \%$ Tween-200), the membrane was incubated overnight at $4^{\circ} \mathrm{C}$ with primary antibodies against $\operatorname{LOX}(1: 4,000$; Novus), E-cadherin (1:1,000; Cell Signaling Technology), $\alpha$-SMA (1:200; Abcam), vimentin (1:1,000; Cell Signaling Technology), MMP-2 (1:1,000; Boster), MMP-9 (1:1,000; Boster), tubulin (1:5,000; Thermo Scientific IHC, Fremont,
CA, USA), GAPDH (1:2,000; Cell Signaling Technology). After washing with TBST three times each for $5 \mathrm{~min}$, membranes were incubated with the corresponding secondary antibody (1:2,000; Cell Signaling Technology) conjugated with horseradish peroxidase for $1 \mathrm{~h}$ at room temperature. After washing, blots were developed with an enhanced chemiluminescence system (Molecular Imager ChemiDoc XRS+ System, Bio-Rad). Protein bands were quantitated by the 1D ScanEX software (Scananalytics, Fairfax, VA, USA). Experiments shown here were repeated at least 3 times with reproducible results and a representative one is presented, unless otherwise indicated.

LOX activity assay. Cervical carcinoma cells in phenol red-free DMEM were incubated in normoxia or hypoxia. The conditioned medium was collected and LOX activity was assayed using diaminopentane as a substrate in the Amplex Red fluorescence assay $(29,30)$. The reaction mixture consisted of $1.2 \mathrm{~mol} / 1$ urea, $0.05 \mathrm{~mol} / 1$ sodium borate $(\mathrm{pH} 8.2)$, $10 \mathrm{mmol} / \mathrm{l}$ diaminopentane, $10 \mu \mathrm{mol} / \mathrm{l} \mathrm{Amplex} \mathrm{red} \mathrm{and} 1 \mathrm{U} / \mathrm{ml}$ horseradish peroxidase in a final volume of $1 \mathrm{ml}$. Conditioned medium $(500 \mu \mathrm{l})$ was added to the reaction mixture in the presence or absence of $0.5 \mathrm{mmol} / 1$ aminopropionitrile (BAPN; Sigma), an active site inhibitor of LOX. Samples were incubated at $37^{\circ} \mathrm{C}$ for $30 \mathrm{~min}$, placed on ice, and then recorded at an excitation wavelength of $563 \mathrm{~nm}$ and emission wavelength of $587 \mathrm{~nm}$ (31). All enzyme activities were calculated as the increase of fluorescent units above background levels of BAPN controls and normalized to total cell protein (28).

In vitro invasion and migration assay. Cells were serumdeprived for $24 \mathrm{~h}$, seeded at a density of 50,000 cells/well on the top of Matrigel-coated filters, moved to chambers containing $600 \mu \mathrm{l}$ of $10 \% \mathrm{FBS}$ as a chemo-attractant and incubated under normoxia or oxygen-deprived conditions for $48 \mathrm{~h}$. BAPN $(500 \mu \mathrm{M})$ was added to the culture $24 \mathrm{~h}$ before oxygen deprivation and continued throughout the experiment (19). At the same time, equal cells were plated into 96-well plates for cell number assay (MTT). The cells (treated and untreated) were incubated at $37^{\circ} \mathrm{C}$ under normoxia or oxygen-deprived conditions for $48 \mathrm{~h}$ and then the Matrigel was removed with a cotton bud. The invaded cells were fixed, stained with hematoxylin and counted. The invasiveness of cervical carcinoma cells was determined by the percentage-of-invasion score (invaded cell number/total cell number 100\%) (32). Experiments were repeated three times. The in vitro cellular migration assay was based on the described membrane invasion culture system, but differed in the use of filters not Matrigel-coated.

Morphological evaluation. Cell morphology was studied during the indicated time course using an Olympus (Melville, NY, USA) IX71 inverted microscope.

Statistical analysis. Data are presented as the means \pm standard deviation of 3 separate experiments. Significance of the differences between the experimental conditions was determined by one-way ANOVA followed by Bonferroni's test. A P-value $<0.05$ was considered to indicate statistically significant differences and a P-value $<0.01$ was considered to indicate statistically very significant differences. 
A
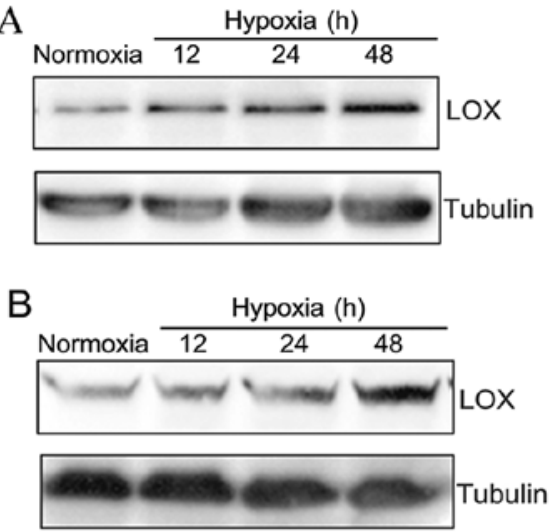

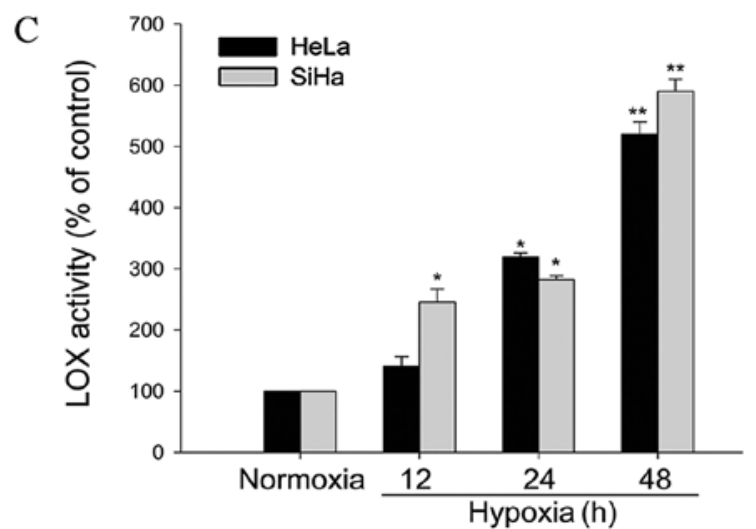

Figure 1. The time course of LOX protein expression and catalytic activity in cervical cancer cells under hypoxia. Hypoxia induced LOX protein expression in (A) HeLa and (B) SiHa cells. Cells were incubated under normoxia or hypoxia for 12, 24 and 48 h. Cell proteins were extracted for western blot analysis as described in Materials and methods. Tubulin was used as an internal control. (C) Effect of hypoxia on LOX activity in cervical carcinoma cells. Cervical carcinoma cells were cultured under normoxia or hypoxia for 12, 24 and $48 \mathrm{~h}$. The conditioned media were collected and LOX activity was assayed. Data shown are the means $\pm \mathrm{SD}(\mathrm{n}=3) .{ }^{*} \mathrm{P}<0.05,{ }^{* *} \mathrm{P}<0.01$ compared with control.

\section{Results}

Upregulation of LOX at protein and catalytic levels in cervical cancer cells under hypoxic conditions. To explore the effect of hypoxia on LOX protein expression, we performed western blot assays in HeLa and SiHa cells incubated under hypoxic conditions for various time points over a 48 -h period. As shown in Fig. 1, hypoxia enhanced LOX protein expression in a time course-dependent manner amounting to 1.48 -, 1.74- and 2.07-fold of the control (52.6 density units) for HeLa cells (Fig. 1A), and 1.09-, 1.49- and 2.24-fold of the control (41.0 density units) for SiHa cells (Fig. 1B), respectively, at 12, 24 and 48-h time points. Furthermore, LOX catalytic assays indicated significant increases in the LOX activity by hypoxia in the conditioned media reaching 1.5-, 3.2- and 5.2-fold of the control for HeLa cells and 2.5-, 2.8- and 6.2-fold of the control for SiHa cells, respectively, at the same time points as described (Fig. 1C).

BAPN inhibition of hypoxia-induced invasion of cervical cancer cells. The first step of the cancer metastatic process is cell invasion. To study the effect of LOX inhibition with cervical carcinoma cell behavior, we examined the invasion of HeLa and SiHa cells in vitro. Both cell lines were incubated on Matrigel-coated filters of transwells for $48 \mathrm{~h}$ under normoxia or hypoxia in the presence or absence of $500 \mu \mathrm{M}$ BAPN, an inhibitor of LOX. Following incubation, trans-filter (invasion) cells were stained (Fig. 2A and B) and numbers counted (Fig. 2C and D). As shown, two cell lines showed strong invasion phenomenon under hypoxia in comparison to normoxia. Notably, BAPN that inactivates LOX activity significantly reduced hypoxia-elicited cell invasion in both cell models (Fig. 2A and B). Counting of invasive cell number further illustrated morphological conclusion. As shown (Fig. 2C and D), hypoxia enhanced cancer cell invasion to 220 and $250 \%$ of the control, which were suppressed to 50 and $60 \%$ of the control in HeLa and SiHa cells, respectively, in the presence of $500 \mu \mathrm{M}$ BAPN. Thus, LOX plays a key role in the development of invasion of cervical carcinoma cells.
BAPN inhibition of hypoxia-induced migration of cervical cancer cells. Migration is essential for cancer cell motility and crucial for primary metastatic growth. Using the transwell assay we further evaluated BAPN effects on the migration of cervical carcinoma cells. As shown in morphological studies, enhancement of migration was observed in HeLa (Fig. 3A) and SiHa (Fig. 3B) cells under hypoxic conditions which was antagonized in the presence of $500 \mu \mathrm{M}$ BAPN. This was confirmed by cell number counting such that hypoxia increased cancer cell migration to 180 and $240 \%$ of the control, which were decreased to 60 and $70 \%$ of the control in HeLa (Fig. 3C) and SiHa cells (Fig. 3D), respectively, in the presence of $500 \mu \mathrm{M}$ BAPN. Thus, LOX facilitates hypoxia-induced migration of cervical carcinoma cells.

Hypoxia induces epithelial-mesenchymal transition in cervical cancer cells. Phase-contrast microscopy showed morphological alterations in cervical carcinoma cells from the flatting, contacting and spreading form under normoxia to the elongating, spindle shape under hypoxia suggesting the loss of epithelial features and the gain of mesenchymal phenotypes of these cancer cells. Thus, hypoxia may induce EMT in cervical carcinoma cells. To test this possibility, we examined expressions of E-cadherin, $\alpha$-SMA and vimentin, the EMT molecular markers, by western blotting in our cancer cell models. Consistent with the morphological changes, hypoxia induced downregulation of E-cadherin, an epithelial marker, in HeLa (Fig. 4A) and SiHa cells (Fig. 4B) in a time course-dependent manner. Reductions of E-cadherin in HeLa and SiHa cells amounted to 76, 49 and 3\% of the control (142.5 density units) for HeLa cells, and 84, 64 and $21 \%$ of the control (128.5 density units) for SiHa cells, respectively, at 12, 24 and 48-h hypoxia incubation. Simultaneously, mesenchymal marker proteins, vimentin and $\alpha$-SMA were increased to 3.0-, 3.5- and 5.0-fold of the control (19.0 density units), and 1.1-, 1.4- and 2.0-fold of the control (25.1 density units) for HeLa cells (Fig. 4C), and 4.2-, 4.6- and 4.3-fold of the control (51.9 density units), and 1.2-, 1.25- and 20.5-fold of the control (6.3 density units) for SiHa cells (Fig. 4D), respectively, under 


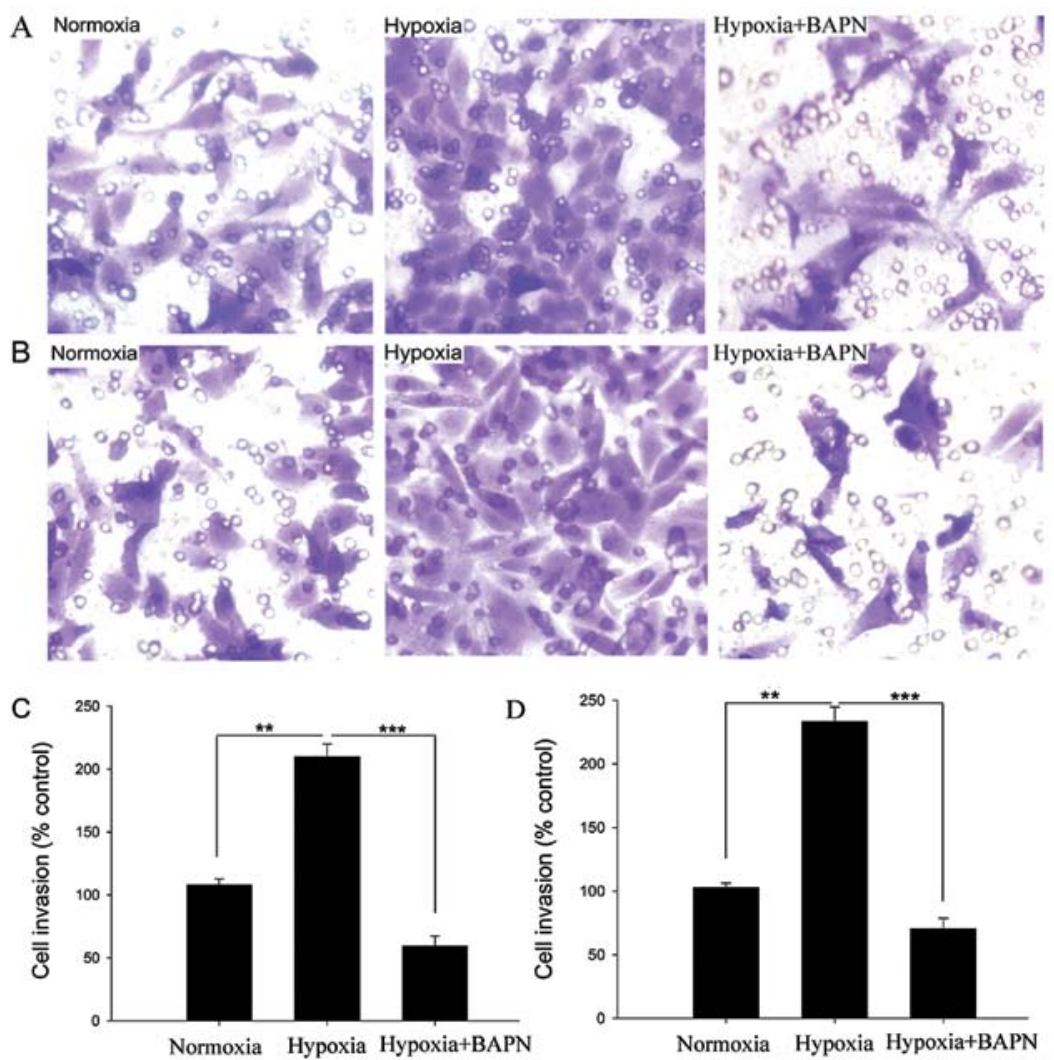

Figure 2. BAPN inhibition of hypoxia-induced invasion in cervical cancer cells. (A and C) HeLa and (B and D) SiHa cells were cultured under normoxia or hypoxia for $48 \mathrm{~h}$. BAPN at $500 \mu \mathrm{M}$ was added to the culture $24 \mathrm{~h}$ before hypoxia and the incubation continued throughout the experiment. The invaded cells were fixed, stained with hematoxylin (A and B), and counted (C and D). Data in $\mathrm{C}$ and $\mathrm{D}$ are the means $\pm \mathrm{SD}(\mathrm{n}=3) .{ }^{* *} \mathrm{P}<0.01,{ }^{* * *} \mathrm{P}<0.001$ compared with control or hypoxia. (A and B) Original magnification, $\mathrm{x} 200$.
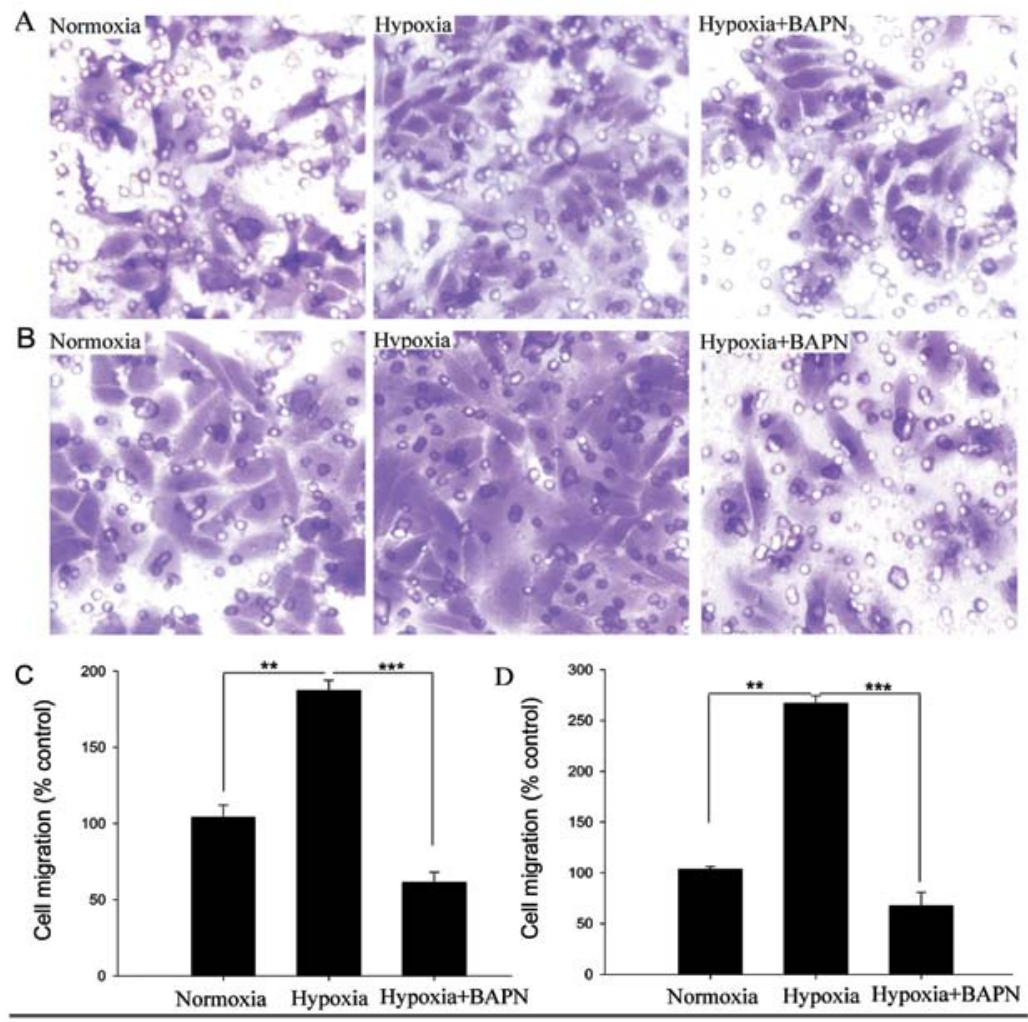

Figure 3. BAPN inhibition of hypoxia-induced migration in cervical cancer cells. (A and C) HeLa and (B and D) SiHa cells were cultured under normoxia or hypoxia for $48 \mathrm{~h}$. BAPN at $500 \mu \mathrm{M}$ was added to the culture $24 \mathrm{~h}$ before hypoxia and incubation continued throughout the experiment. The migrated cells were fixed, stained with hematoxylin (A and B), and counted (C and D). Data in $\mathrm{C}$ and $\mathrm{D}$ are the means $\pm \mathrm{SD}(\mathrm{n}=3) .{ }^{* *} \mathrm{P}<0.01,{ }^{* * *} \mathrm{P}<0.001$ compared with control or hypoxia. (A and B) Original magnification, x200. 

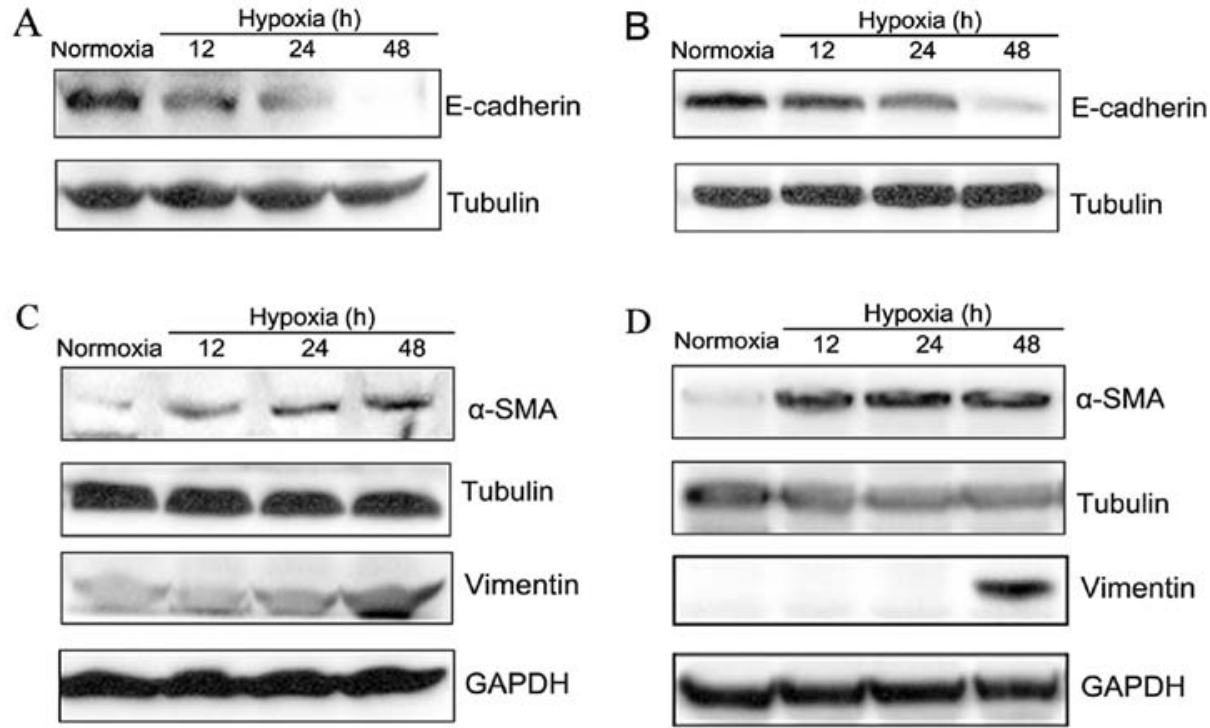

Figure 4. Time course of hypoxia-induced EMT protein marker expression in cervical cancer cells. (A and C) HeLa and (B and D) SiHa cells were incubated under normoxia or hypoxia for 12, 24 and $48 \mathrm{~h}$. Cell proteins were extracted for western blot analysis to assess expressions of E-cadherin (A and B), and (C and D) $\alpha$-SMA and vimentin. Tubulin or GAPDH was used as an internal control.
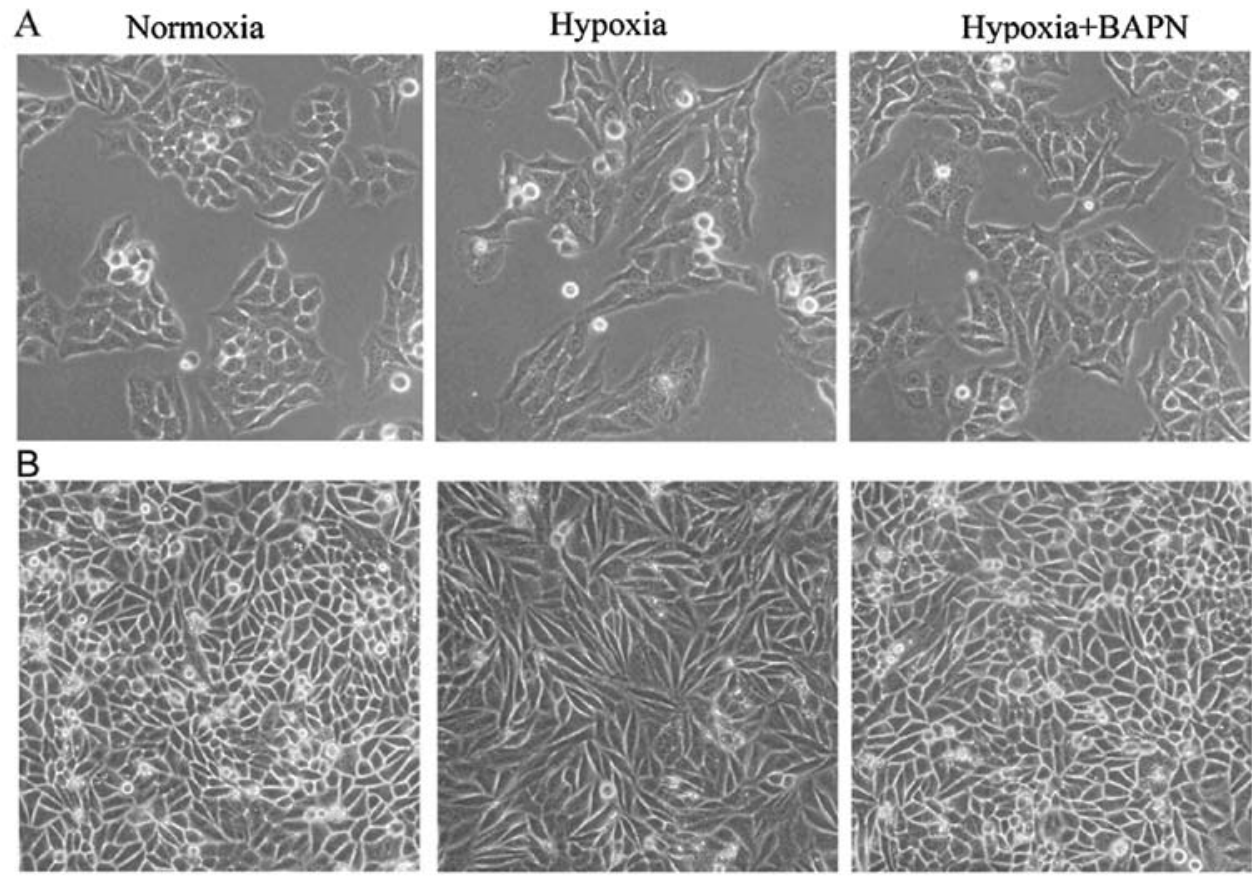

Figure 5. BAPN abolishment of the EMT morphological alterations in cervical cancer cells. HeLa and SiHa cells were incubated under normoxia or hypoxia for $48 \mathrm{~h}$ with or without $500 \mu \mathrm{M}$ BAPN. BAPN at $500 \mu \mathrm{M}$ was added to the culture $24 \mathrm{~h}$ before hypoxia and incubation continued throughout the experiment. Morphological changes of (A) HeLa and (B) SiHa cells were observed under the phase contrast microscope. (A and B) Original magnification, x200.

hypoxia for 12, 24 and $48 \mathrm{~h}$. Thus, downregulation of epithelial marker, E-cadherin, and upregulation of mesenchymal markers, $\alpha$-SMA and vimentin, were associated with cervical carcinoma cells under hypoxia indicating EMT occurred in such cell models under our experimental conditions.

BAPN abolishment of the EMT morphological alterations in HeLa and SiHa cells. To answer whether BAPN inhibits hypoxia-induced EMT in cancer cell models, we examined BAPN effects on morphological changes in cervical carci- noma cells under hypoxia with phase contrast microscopy. $\mathrm{HeLa}$ and $\mathrm{SiHa}$ cells exposed to hypoxia for $48 \mathrm{~h}$ displayed morphological changes towards a mesenchymal-like appearance (Fig. 5). Anoxic HeLa and SiHa cells were no longer able to form 'cobblestone' clusters typical for epithelial cells, but acquired a more elongated, spindle-like morphology, a critical marker of EMT. These morphological changes were involved in cervical carcinoma cell invasion and migration under hypoxia (33). This is based on findings that BAPN inhibited tumor cell invasion and migration (Figs. 2 and 3) antagonized 
Table I. Densitometry measurement of BAPN effects on the expression of EMT marker proteins in HeLa and SiHa cells under hypoxia.

\begin{tabular}{|c|c|c|c|c|c|c|c|}
\hline \multirow[b]{2}{*}{ EMT markers } & \multirow[b]{2}{*}{ Cell lines } & \multicolumn{2}{|c|}{ Normoxia } & \multicolumn{2}{|c|}{ Hypoxia } & \multicolumn{2}{|c|}{ Hypoxia+BAPN $(100 \mu \mathrm{M})$} \\
\hline & & Density units & $(\%)$ & Density units & $(\%)$ & Density units & $(\%)$ \\
\hline \multirow[t]{2}{*}{ E-cadherin } & HeLa & 103.0 & 100 & 84.0 & 81.6 & 95.0 & 92.2 \\
\hline & $\mathrm{SiHa}$ & 129.1 & 100 & 18.3 & 14.2 & 97.1 & 75.2 \\
\hline \multirow[t]{2}{*}{$\alpha$-SMA } & $\mathrm{HeLa}$ & 105.0 & 100 & 144.0 & 137.1 & 89.8 & 85.5 \\
\hline & $\mathrm{SiHa}$ & 44.8 & 100 & 98.6 & 220.1 & 53.0 & 118.3 \\
\hline \multirow[t]{2}{*}{ Vimentin } & HeLa & 10.7 & 100 & 213.2 & 1992.5 & 22.4 & 209.3 \\
\hline & $\mathrm{SiHa}$ & 4.4 & 100 & 69.3 & 1575.0 & 3.4 & 77.3 \\
\hline \multirow[t]{2}{*}{ MMP-2 } & $\mathrm{HeLa}$ & 62.9 & 100 & 78.6 & 125.0 & 59.5 & 94.6 \\
\hline & $\mathrm{SiHa}$ & 79.2 & 100 & 76.9 & 97.1 & 71.3 & 90.0 \\
\hline \multirow[t]{2}{*}{ MMP-9 } & HeLa & 128.0 & 100 & 104.2 & 81.3 & 53.0 & 41.4 \\
\hline & $\mathrm{SiHa}$ & 47.5 & 100 & 78.3 & 164.8 & 42.2 & 88.4 \\
\hline
\end{tabular}
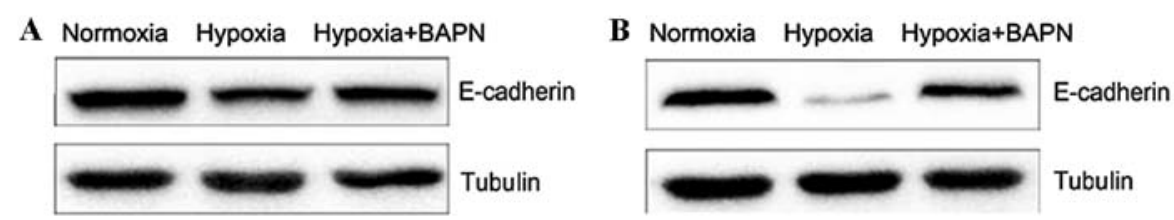

C Normoxia Hypoxia Hypoxia+BAPN

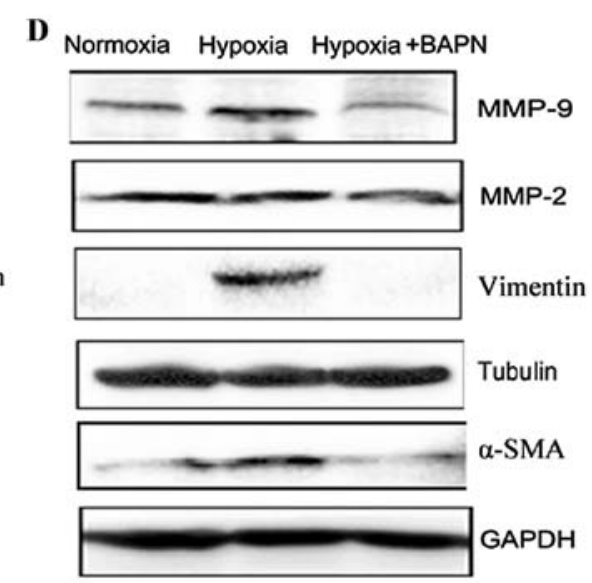

Figure 6. BAPN antagonism of hypoxia-induced changes of EMT marker proteins in cervical cancer cells. (A and C) HeLa and (B and D) SiHa cells were incubated under normoxia or hypoxia for $48 \mathrm{~h}$ with or without $500 \mu \mathrm{M}$ BAPN. BAPN at $500 \mu \mathrm{M}$ was added to the culture $24 \mathrm{~h}$ before hypoxia and incubation continued throughout the experiment. Cell proteins were extracted for western blot analysis to assess expression of E-cadherin (A and B), and $\alpha$-SMA, vimentin, MMP-2 and MMP-9 (C and D). Tubulin or GAPDH was used as an internal control. Protein bands were measured for densities using the 1D ScanEX software.

morphological changes in cancer cells under hypoxia, and reversed cell phenotypes similar to those under normoxia. Thus, BAPN prevented HeLa and SiHa cells from hypoxiainduced morphological changes toward the EMT.

$B A P N$ antagonism of hypoxia-induced changes of EMT marker proteins in HeLa and SiHa cells. Finally, we detected the effects of BAPN on the expressions of E-cadherin, $\alpha$-SMA, vimentin, MMP-2 and MMP-9 proteins, the EMT markers, in
HeLa and SiHa cells exposed to hypoxia for $48 \mathrm{~h}$. As shown, BAPN effectively prevented hypoxia-induced downregulation of E-cadherin (Fig. 6A and B) and strongly inhibited hypoxiainduced upregulation of $\alpha$-SMA and vimentin (Fig. 6C and D). Although MMP-2 in HeLa and SiHa cells was not changed significantly under hypoxia or hypoxia plus BAPN, MMP-9 in both cell lines was markedly changed in response to experimental conditions (hypoxia and BAPN treatment). MMP-9 expression was increased by hypoxia in $\mathrm{SiHa}$ cells up to 
1.65-fold of the control (47.5 density units) and turned to 0.88 of the control (47.5 density units) in the presence of $500 \mu \mathrm{M}$ BAPN. Furthermore, BAPN also reduced MMP-9 expression to 0.41 of the control (128 density units) in HeLa cells in response to hypoxia. Densitometry data of BAPN effects on EMT marker proteins are presented in Table I. These results are consistent with BAPN effects on tumor cell invasion and migration, strongly supporting the conclusion that LOX is an essential factor for modulation of hypoxia-induced EMT, invasion and migration of cervical cancer cells.

\section{Discussion}

In the present study, we showed that stimulation of cervical cancer cells with hypoxia triggers LOX activation consistent with elevation of this enzyme in several types of cancer (34-36). LOX is known as a hypoxia-responsive gene and is known to be regulated at the messenger RNA level by hypoxia-inducible factor-1 (HIF-1) (19,35,36). Enhancement of LOX protein expression and enzyme activities in cervical cancer cells upon hypoxia exposure suggests LOX as critical factor modulating cancer cell behavior.

Implication of LOX in cancer development and progression is more controversial (37). A large volume of literature reports downregulation of LOX in various malignancies such as basal and squamous cell, bronchogenic, colon, esophageal, gastric, and head and neck squamous cell cancer, as well as in pancreatic, prostatic carcinomas, and melanoma (38). LOX propeptide reverses the invasive phenotype of Her-2/neudriven breast cancer (15). By contrast, our findings in this study indicate hypoxia-induced upregulation of LOX promoting invasion and migration in cervical cancer cells in vitro. One possible explanation for this controversy is that LOX impact on tumorigenic properties may depend on the tumorigenic tissue types, microenvironment and expressions of various LOX and LOX-like proteins in different organs (37).

We discovered a novel role of LOX in the modulation of hypoxia-induced EMT, invasion and migration of cervical cancer cells. EMT occurs during critical phases of embryonic development. Epithelial and mesenchymal cells each provide distinct specific biological functions (25). Epithelial cells can form 'cobblestone' clusters, display polar morphology, welldeveloped cell-cell adhesion and cell contact inhibition, and E-cadherin expression. On the contrary, mesenchymal cells exhibit elongated, spindle-like morphology, strong cell motility, have focal adhesions, express $\alpha$-SMA, vimentin and transcription factors Snail, Slug and Twist (37). During the transition, polarized epithelial cells are converted into motile cells, and epithelial morphology turns into fibroblastic phenotype. EMT is not only a critical phase of embryonic development, but also provides a mechanism for cancer progression (39). Cancer cells use EMT to overcome cell-cell adhesion constraints and gain a migratory phenotype. Therefore, EMT is a fundamental process for cancer cell invasion and migration.

E-cadherin mediates homophilic interactions by forming adhesive bonds between one or several immunoglobulin domains in their extracellular region and connecting to actin microfilaments. E-cadherin is required for adhering junctions and maintaining epithelial phenotype. E-cadherin also regulates cell proliferation. Loss of E-cadherin expression is strongly involved in EMT $(39,40)$. We herein report that hypoxia downregulated E-cadherin expression, consistent with the early publication regarding HIF-1 and Notch regulation of E-cadherin. Although Notch signaling has been shown to indirectly upregulate expression of LOX, direct evidence for LOX modulation of the EMT has yet to be described (23). $\alpha$-SMA and vimentin are often used to define the mesenchymal phenotype (41). MMP-2 and MMP-9 play critical roles in tumor invasion and development of metastases $(42,43)$. In this study, hypoxia-induced expressions of mesenchymal markers, $\alpha$-SMA, vimentin and MMP-9, were blocked by BAPN, an active site inhibitor of LOX. Simultaneously, BAPN inhibition of LOX can also reverse hypoxia-induced invasion and migration of cervical cancer cells. Thus, LOX is a critical effector for hypoxia-induced metastasis mediated by facilitating EMT of cancer cells.

It should be noted that cell invasion and migration are complex, multi-step processes. The critical role of LOX in invasion and migration of cancer cells may also be mediated by other mechanisms in addition to stimulating EMT. LOX has been reported to promote BMDC adhesion and invasion by crosslinking collagen IV in basement membranes (16). LOX has chemotactic activity modulating organization of actin filaments and focal adhesions essential for cell migration (44). Inhibition of LOX decreased focal adhesion kinase (FAK) and PI3K activities, impeded malignancy and lowered tumor incidence (17). Thus, the development of drugs targeting LOX may have therapeutic significance for the prevention and treatment of hypoxia-induced tumor metastasis.

\section{Acknowledgements}

This study was supported by research grants from the Chinese Ministry of Education for returnees and the National Natural Science Foundation of China (no. 30772606).

\section{References}

1. Sobti RC, Singh N, Hussain S, Suri V, Nijhawan R, Bharti AC, Bharadwaj $\mathrm{M}$ and Das BC: Aberrant promoter methylation and loss of suppressor of cytokine signalling-1 gene expression in the development of uterine cervical carcinogenesis. Cell Oncol 34: 533-543, 2011.

2. Chandra S, Barola N and Bahadur D: Impedimetric biosensor for early detection of cervical cancer. Chem Commun 47: 11258-11260, 2011.

3. Jemal A, Bray F, Center MM, Ferlay J, Ward E and Forman D: Global cancer statistics. CA Cancer J Clin 61: 69-90, 2011.

4. Qiang R, Wang F, Shi LY, Liu M, Chen S, Wan HY, Li YX, Li X, Gao SY, Sun BC and Tang H: Plexin-B1 is a target of miR-214 in cervical cancer and promotes the growth and invasion of HeLa cells. Int J Biochem Cell Biol 43: 632-641, 2011.

5. Ng MR and Brugge JS: A stiff blow from the stroma: collagen crosslinking drives tumor progression. Cancer Cell 16: 455-457, 2009.

6. Trackman PC, Bedell-Hogan D, Tang J and Kagan HM: Posttranslational glycosylation and proteolytic processing of a lysyl oxidase precursor. J Biol Chem 267: 8666-8671, 1992.

7. Zhao Y, Chen L, Gao S, Toselli P, Stone P and Li W: The critical role of the cellular thiol homeostasis in cadmium perturbation of the lung extracellular matrix. Toxicology 267: 60-69, 2010.

8. Viguet-Carrin S, Garnero P and Delmas PD: The role of collagen in bone strength. Osteoporos Int 17: 319-336, 2006.

9. Smith-Mungo LI and Kagan HM: Lysyl oxidase: properties, regulation and multiple functions in biology. Matrix Biol 16: 387-398, 1998 
10. Kagan HM and Li W: Lysyl oxidase: properties, specificity, and biological roles inside and outside of the cell. J Cell Biochem 88: 660-672, 2003

11. Ferns GA, Lamb DJ and Taylor A: The possible role of copper ions in atherogenesis: the Blue Janus. Atherosclerosis 133: 139-152, 1997.

12. Rodriguez C, Martinez-Gonzalez J, Raposo B, Alcudia JF, Guadall A and Badimon L: Regulation of lysyl oxidase in vascular cells: lysyl oxidase as a new player in cardiovascular diseases. Cardiovasc Res 79: 7-13, 2008.

13. Jeay S, Pianetti S, Kagan HM and Sonenshein GE: Lysyl oxidase inhibits ras-mediated transformation by preventing activation of NF-kappa B. Mol Cell Biol 23: 2251-2263, 2003.

14. Bouez C, Reynaud C, Noblesse E, Thepot A, Gleyzal C, Kanitakis J, Perrier E, Damour O and Sommer P: The lysyl oxidase LOX is absent in basal and squamous cell carcinomas and its knockdown induces an invading phenotype in a skin equivalent model. Clin Cancer Res 12: 1463-1469, 2006.

15. Min C, Kirsch KH, Zhao Y, Jeay S, Palamakumbura AH, Trackman PC and Sonenshein GE: The tumor suppressor activity of the lysyl oxidase propeptide reverses the invasive phenotype of Her-2/neu-driven breast cancer. Cancer Res 67: 1105-1112, 2007.

16. Erler JT, Bennewith KL, Cox TR, Lang G, Bird D, Koong A, Le QT and Giaccia AJ: Hypoxia-induced lysyl oxidase is a critical mediator of bone marrow cell recruitment to form the premetastatic niche. Cancer Cell 15: 35-44, 2009.

17. Levental KR, Yu H, Kass L, Lakins JN, Egeblad M, Erler JT, Fong SF, Csiszar K, Giaccia A, Weninger W, Yamauchi M, Gasser DL and Weaver VM: Matrix crosslinking forces tumor progression by enhancing integrin signaling. Cell 139: 891-906, 2009.

18. Erler JT and Giaccia AJ: Lysyl oxidase mediates hypoxic control of metastasis. Cancer Res 66: 10238-10241, 2006.

19. Erler JT, Bennewith KL, Nicolau M, Dornhofer N, Kong C, Le QT, Chi JT, Jeffrey SS and Giaccia AJ: Lysyl oxidase is essential for hypoxia-induced metastasis. Nature 440: 1222-1226, 2006.

20. Brown JM and Wilson WR: Exploiting tumour hypoxia in cancer treatment. Nat Rev Cancer 4: 437-447, 2004.

21. Vaupel P, Kelleher DK and Hockel M: Oxygen status of malignant tumors: pathogenesis of hypoxia and significance for tumor therapy. Semin Oncol 28: 29-35, 2001.

22. Wilson WR and Hay MP: Targeting hypoxia in cancer therapy. Nat Rev Cancer 11: 393-410, 2011.

23. Sahlgren C, Gustafsson MV, Jin S, Poellinger L and Lendahl U: Notch signaling mediates hypoxia-induced tumor cell migration and invasion. Proc Natl Acad Sci USA 105: 6392-6397, 2008

24. Christofori G: New signals from the invasive front. Nature 441: 444-450, 2006

25. Lee JM, Dedhar S, Kalluri R and Thompson EW: The epithelialmesenchymal transition: new insights in signaling, development, and disease. J Cell Biol 172: 973-981, 2006.

26. Huber MA, Kraut N and Beug H: Molecular requirements for epithelial-mesenchymal transition during tumor progression. Curr Opin Cell Biol 17: 548-558, 2005.

27. Erler JT, Cawthorne CJ, Williams KJ, Koritzinsky M, Wouters BG, Wilson C, Miller C, Demonacos C, Stratford IJ and Dive C: Hypoxia-mediated down-regulation of Bid and Bax in tumors occurs via hypoxia-inducible factor 1-dependent and -independent mechanisms and contributes to drug resistance. Mol Cell Biol 24: 2875-2889, 2004.

28. Chen LJ, Zhao Y, Gao S, Chou IN, Toselli P, Stone P and Li W: Downregulation of lysyl oxidase and upregulation of cellular thiols in rat fetal lung fibroblasts treated with cigarette smoke condensate. Toxicol Sci 83: 372-379, 2005.
29. Chou DK, Zhao Y, Gao S, Chou IN, Toselli P, Stone P and $\mathrm{Li}$ W: Perturbation of copper $(\mathrm{Cu})$ homeostasis and expression of $\mathrm{Cu}$-binding proteins in cadmium-resistant lung fibroblasts. Toxicol Sci 99: 267-276, 2007.

30. Palamakumbura AH and Trackman PC: A fluorometric assay for detection of lysyl oxidase enzyme activity in biological samples. Anal Biochem 300: 245-251, 2002.

31. Chen LJ, Li WD, Li SF, Su XW, Lin GY, Huang YJ and Yan GM: Bleomycin induces upregulation of lysyl oxidase in cultured human fetal lung fibroblasts. Acta Pharmacol Sin 31: 554-559, 2010.

32. Zhu W, Ou Y, Li Y, Xiao R, Shu M, Zhou Y, Xie J, He S, Qiu P and Yan G: A small-molecule triptolide suppresses angiogenesis and invasion of human anaplastic thyroid carcinoma cells via down-regulation of the nuclear factor-kappa B pathway. Mol Pharmacol 75: 812-819, 2009 .

33. Hollosi P, Yakushiji JK, Fong KS, Csiszar K and Fong SF: Lysyl oxidase-like 2 promotes migration in noninvasive breast cancer cells but not in normal breast epithelial cells. Int J Cancer 125: 318-327, 2009.

34. Erler JT and Weaver VM: Three-dimensional context regulation of metastasis. Clin Exp Metastasis 26: 35-49, 2009.

35. Brahimi-Horn C, Mazure N and Pouyssegur J: Signalling via the hypoxia-inducible factor-1alpha requires multiple posttranslational modifications. Cell Signal 17: 1-9, 2005.

36. Wang V, Davis DA, Haque M, Huang LE and Yarchoan R: Differential gene up-regulation by hypoxia-inducible factor1alpha and hypoxia-inducible factor-2alpha in HEK293T cells. Cancer Res 65: 3299-3306, 2005.

37. Pez F, Dayan F, Durivault J, Kaniewski B, Aimond G, Le Provost GS, Deux B, Clezardin P, Sommer P, Pouyssegur J and Reynaud C: The HIF-1-inducible lysyl oxidase activates HIF-1 via the Akt pathway in a positive regulation loop and synergizes with HIF-1 in promoting tumor cell growth. Cancer Res 71: 1647-1657, 2011.

38. Payne SL, Hendrix MJ and Kirschmann DA: Paradoxical roles for lysyl oxidases in cancer - a prospect. J Cell Biochem 101: 1338-1354, 2007

39. Thiery JP: Epithelial-mesenchymal transitions in tumour progression. Nat Rev Cancer 2: 442-454, 2002.

40. Tepass U, Truong K, Godt D, Ikura M and Peifer M: Cadherins in embryonic and neural morphogenesis. Nat Rev Mol Cell Biol 1: 91-100, 2000

41. Willis BC, Liebler JM, Luby-Phelps K, Nicholson AG, Crandall ED, du Bois RM and Borok Z: Induction of epithelial-mesenchymal transition in alveolar epithelial cells by transforming growth factor-betal: potential role in idiopathic pulmonary fibrosis. Am J Pathol 166: 1321-1332, 2005.

42. Wu YY, Peck K, Chang YL, Pan SH, Cheng YF, Lin JC, Yang RB, Hong TM and Yang PC: SCUBE3 is an endogenous TGF-beta receptor ligand and regulates the epithelial-mesenchymal transition in lung cancer. Oncogene 30: 3682-3693, 2011.

43. Yoo YA, Kang MH, Lee HJ, Kim BH, Park JK, Kim HK, Kim JS and Oh SC: Sonic hedgehog pathway promotes metastasis and lymphangiogenesis via activation of Akt, EMT, and MMP-9 pathway in gastric cancer. Cancer Res 71: 7061-7070, 2011.

44. Li W, Liu G, Chou IN and Kagan HM: Hydrogen peroxide-mediated, lysyl oxidase-dependent chemotaxis of vascular smooth muscle cells. J Cell Biochem 78: 550-557, 2000. 